Part of Journal of Research of the National Bureau of Standards, Volume 19, July 1937

\title{
WICK TEST FOR EFFLORESCENCE OF BUILDING BRICK
}

\author{
By John W. McBurney and Douglas E. Parsons
}

\begin{abstract}
This paper describes the wick test for efflorescence on building bricks and presents data showing the relation between results of wick tests and the appearance of efflorescence on exposed masonry panels. It is concluded that the results of the 5 -day wick test correlate well with the grading on exposed panels when the efflorescence on individual bricks rated in excess of "moderate" on the scale used for grading intensity of visible efflorescence.
\end{abstract}

CONTENTS Page

I. Introduction

II. Wick test for efflorescence

III. Exposure tests of panels of brick masonry

IV. Relation between indications of wick tests on brick and efflorescence on exposed masonry panels................. 108

V. Summary and conclusions_............... 109

\section{INTRODUCTION}

If a brick is set on end in shallow water and that portion of the brick above the water is exposed to conditions favoring evaporation, water entering the brick by capillarity will move upward and outward through the brick. The water will tend to dissolve soluble salts in the brick and transport them to its surface where they may be progressively deposited as the water, in which they are dissolved, evaporates. These phenomena have been variously applied in a "wick test" which may be regarded as a test to indicate the presence of soluble salts which may contribute to efflorescence on masonry.

The authors of this report do not know who first used this test for efflorescence, but one of the authors tested brick by this method in 1922. Palmer ${ }^{1}$ reported, "The brick were set vertically in the pan and in about 1 inch of distilled water, and the tests in all cases were continued for a period of 6 months." Butterworth ${ }^{2}$ used a wick test. with exposure from 2 to 3 weeks. In 1930, 5-day wick tests were made on 684 bricks, each of a different grade or brand, from 255 manufacturers. Although the results of these tests were not published they were given to the manufacturers supplying the samples. Since 1930 considerable use of the wick test has been made by the National Bureau of Standards at the request of certain Government construction agencies.

In the late summer of 1936 a number of small panels or wallettes were constructed from 18 types of brick for the purpose of studying: the effects of weather on brick masonry, including efflorescence. Samples of the brick used in constructing these panels were subjected

1 BS Tech Pap. 22, 584 (1928) T370.

2 B. Butterworth, Contributions to the study of florescences, Trans. Ceram. Soc. 32, 270 (1933). 
to the 5-day wick test. The relation between the results of this wick test on the brick and the amount of apparent efflorescence on these panels is considered in this paper.

\section{WICK TEST FOR EFFLORESCENCE}

At the National Bureau of Standards, the wick test consists in standing a whole brick on end in 0.5 inch of distilled water, maintained at approximately a constant level by inverting a flask of water over the tray, with the mouth of the flask held at the desired level. The brick, except that portion in contact with water, is exposed to the air of the laboratory at ordinary temperature. At the end of 5 days the brick is dried in an oven at $105^{\circ}$ to $110^{\circ} \mathrm{C}$ for at least $18 \mathrm{hr}$, and the amount of efflorescence is estimated by visual comparison with an untreated specimen.

The amount of efflorescence is rated on a scale consisting of six classifications or grades, described as follows:

None $(0)$.- No observable difference in the appearances of a brick after test and before.

Trace (1).-Efflorescence barely distinguishable by careful comparison.

Slight (2).-Observable. Not sufficient efflorescence to materially affect the appearance when viewed at a distance of approximately 6 feet.

Moderate (3).-Distinct coating, but the original color of the brick distinguishable under the efflorescence.

Considerable (4).- The original color of the brick masked by the efflorescence.

Abundant (5).-Efflorescence in such quantity that it may be brushed off readily.

It is considered that Butterworth's ${ }^{3}$ first grade, "bricks that are not liable to efflorescence, i. e., those on which the efflorescence developed in the test is nil or negligible", corresponds to the "none", "trace", and "slight" of this grading. His second grade, "bricks that can only be recommended with reserve from the point of view of efflorescence", represents "moderate" and possibly "considerable", and the third grade, "bricks the use of which would constitute a disaster", corresponds to "abundant."

In the wick test on a particular brick, the amount of efflorescence that appears on the surface is affected by several factors other than the quantity of salts per unit of volume of the brick. ${ }^{4}$ For example, if the brick has a very low rate of absorption, approximate equilibrium will be quickly reached between water evaporated and water diffusing through the brick by capillarity. Efflorescence will, under these conditions, appear at the junction between the damp and dry portions of the brick, usually as a horizontal band around the brick. On one specimen, this band was less than 1 inch above the surface of the water. Obviously, the dry portion of this brick did not contribute to the efflorescence. Again, there are certain combinations of temperature, humidity, circulation of air, and pore structure in which evaporation will take place beneath the surface of the brick with the result that some salts will be deposited there and hence will not be

\footnotetext{
3 See footnote 2.

4 If standardization of the wick test is to be attempted, one might begin by prescribing the temperature, humidity, and velocity of air and then working either for a definite time or until a definite quantity of water has been evaporated.
} 
visible. This is the "cryptoflorescence" referred to by Cooling. ${ }^{5}$ Then, too, if the brick specimen has a large total absorption, a high rate of absorption, and contains a moderate amount of readily soluble salts, the effiorescence obtained in the wick test may appear as beads on the four upper corners of the brick instead of being distributed over the surface.

\section{EXPOSURE TESTS OF PANELS OF BRICK MASONRY}

The panels considered in this study of the relations between the results of the wick test and the actual exposures were made of 18 brands of brick (briefly described in table 1) and a single kind of mortar (1.0 portland cement:0.1 hydrated lime:3.0 sand, by weight). All panels are 4 feet high, 3 feet long, and 12 inches thick, and they are set vertically 12 inches deep in the ground. Common bond was used throughout and the workmanship was characterized by furrowing of the horizontal joints and a minimum filling of the vertical joints.

TABLE 1.-Comparison of results of 5-day wick tests for efforescence of brick and efflorescence ratings for masonry panels

\begin{tabular}{|c|c|c|c|c|c|c|c|c|c|c|c|c|}
\hline \multirow{3}{*}{ Brick } & \multirow{3}{*}{$\begin{array}{l}\text { Wick- } \\
\text { test } \\
\text { rat- } \\
\text { ings a }\end{array}$} & \multicolumn{8}{|c|}{ Ratings for masonry panels a } & \multirow{2}{*}{\multicolumn{2}{|c|}{$\begin{array}{c}\text { Absorp- } \\
\text { tion data b }\end{array}$}} & \multirow{3}{*}{ Description of bricks $\circ$} \\
\hline & & \multicolumn{4}{|c|}{$\begin{array}{l}\text { First inspection } \\
\text { of panels with } \\
\text { protection }\end{array}$} & \multicolumn{4}{|c|}{$\begin{array}{l}\text { Second inspec- } \\
\text { tion of panels } \\
\text { with protection }\end{array}$} & & & \\
\hline & & $a$ & $b$ & $c$ & $d$ & $a$ & $b$ & $c$ & $d$ & $C / B$ & $B$ & \\
\hline$-1-1$ & 0 & 4 & 3 & 3 & 3 & 2 & 2 & 2 & 2 & 0.69 & $\begin{array}{c}(\%) \\
24\end{array}$ & $S M$; $C$; salmon, Pennsylvania. \\
\hline 2 & 0 & 1 & 2 & 2 & 0 & 1 & 2 & 1 & 1 & .81 & 15 & $D P ; C ;$ Virginia. \\
\hline & 0 & 1 & 1 & 0 & 2 & 1 & 1 & 1 & 1 & .71 & 18 & Sandlime, Pennsylvania. \\
\hline $4 \ldots$ & 0 & 2 & 1 & 3 & 2 & 1 & 1 & 1 & 1 & .71 & 12 & $S C ; C ;$ Maryland. \\
\hline 5 & 1 & 4 & 3 & 3 & d 1 & 2 & 2 & 2 & 2 & .74 & 17 & SM; $C$; hard, Pennsylvania. \\
\hline 6 & 1 & 2 & 1 & 2 & 1 & 3 & 3 & 3 & 3 & .75 & 15 & $E C ; C$; Chicago. \\
\hline & 2 & 3 & 4 & 3 & 3 & 4 & 3 & 3 & 3 & .87 & 24 & $S M ; C ;$ Detroit. \\
\hline $8 \ldots$ & 2 & 3 & 4 & 3 & 4 & 3 & 2 & 1 & 3 & .91 & 33 & $S C ; C ;$ Wisconsin. \\
\hline $9 \ldots$ & 3 & 0 & 1 & 1 & 1 & 2 & 1 & 2 & 2 & .86 & 14 & $S C$; S; light hard, West Virginia. \\
\hline 10 & 4 & 4 & 3 & 3 & 1 & 4 & 3 & 4 & 3 & .88 & 14 & $D P ; S ;$ Texas. \\
\hline $11 \ldots$ & 4 & 4 & 4 & 4 & 3 & 4 & 4 & 4 & 3 & .83 & 21 & SM; $C$; hard, Hudson Valley. \\
\hline $12 \ldots \ldots$ & 4 & 5 & 4 & 4 & 4 & 3 & 4 & 3 & 3 & .90 & 23 & $S M ; C$; salmon, Hudson Valley. \\
\hline $13 \ldots \ldots$ & $\begin{array}{l}4 \\
4\end{array}$ & $\begin{array}{l}5 \\
4\end{array}$ & 4 & 5 & 4 & 3 & 3 & 3 & 3 & .84 & 18 & $S M$; $C$; saimon, New England. \\
\hline & & & -- & - & -+- & 4 & $-\cdots$ & --- & $-\cdots$ & .86 & 11 & SC; S; deaired, Pennsylvania. \\
\hline ....... & 0 to 2 & 0 & 1 & 2 & 0 & 2 & 2 & 2 & 1 & .57 & 5 & $S C ; S ;$ hard, West Virginia. \\
\hline 16 & 0 to 5 & e 2 & e 1 & 3 & 0 & 3 & 2 & 3 & 2 & .64 & 16 & $S C ; S ;$ Minnesota. \\
\hline 17 & 1 to 3 & 3 & 2 & 2 & 2 & 2 & 1 & 2 & 1 & .78 & 33 & $D P ; C$; Texas. \\
\hline $18 \ldots$ & 2 to 3 & 1 & 1 & 2 & 2 & 2 & 2 & 2 & 1 & .84 & 12 & $S C ; C$; salmon, Maryland. \\
\hline
\end{tabular}

a For convenience, the ratings are expressed numerically, as follows: 0 , none; 1 , trace; 2 , slight; 3 , moderate; 4 , considerable; 5 , abundant.

b $C$, water absorption in the 24 -hour submersion test, and $B$, water absorption in the 5 -hour boiling test, described in the Tentative Methods for Testing Brick (ASTM designation C 67-36T), Proc. Am. Soc. Testing Materials 36, I, 780 (1936).

o $S M$, soft mud; $S C$, side cut; $E C$, end cut; $D P$, dry press; $C$, clay; $S$, shale.

d 2 bricks rated 3 .

e 1 brick rated 4 .

Each brand of brick (except 14) was used to build four panels, each of which was "protected" differently, as follows:

$a$ No protection.

${ }^{5}$ L. F. Cooling, Contributions to the study of florescence. II. Evaporation of water from brick, Trans. Ceram. Soc. 29, 39-52 (1930). 
$b$ Top of panel covered with loosely fitting sheet-copper cap.

$c$ Sheet-copper "flashing" in horizontal joint through the panel, 2 inches above ground level.

$d$ Combination of $b$ and $c$. (See fig. 1.)

The panels are placed on top of a gradually sloping and somewhat wooded knoll in the northwest corner of the Bureau's grounds at Washington, D. C. This site was selected so that all panels would be exposed to essentially the same atmospheric conditions. The individual panels, facing east and west, were spaced 5 feet apart between faces and 4 inches apart between ends.

Random samples consisting of 12 specimens each of the 18 brands of brick used in the construction of these panels were subjected to the 5-day wick test.

\section{RELATION BETWEEN INDICATIONS OF WICK TESTS ON BRICK AND EFFLORESCENCE ON EXPOSED MASONRY PANELS}

The masonry panels were inspected on November 30, 1936 and again on March 4, 1937. The first inspection was made 6 weeks after completion of construction of the panels. There had been no rain for 2 weeks preceding this inspection. Subsequent rains temporarily removed all traces of visible salts from the panels. The second inspection took place on the fourth day of clear weather.

The selection of the ratings for efflorescence on the panels was not as simple as for individual bricks, because the ratings assigned to the panels depended to a far greater extent upon the judgment of the inspector. Both intensity and distribution of the efflorescence wree considered. As indicated by footnotes in table 1, some of the bricks in certain panels of bricks 5 and 16 showed much more efflorescence than others during the first inspection. At the time of the second inspection, the efflorescence was more uniformly distributed. In attempting to evaluate or visualize the appearance of the panels it might be stated that ratings less than "moderate" (3) indicate no material change in the appearance of masonry when viewed from a distance of 20 feet.

Table 1 includes the results of the wick tests, the results of these two inspections, and data on the absorption of the bricks. The reader is cautioned against ascribing any cardinal significance to the numerals used in rating efflorescence. It is probable that the difference in the amounts of salts warranting a change of rating from "moderate" (3) to "considerable" (4) was greater than the difference to change from "none" (0) to "moderate" (3).

The data pertaining to bricks 1 to 14 , inclusive, are grouped according to the ratings for these bricks in the wick test. The individual bricks (12 each) of each of these types were rated alike in that test. Those for bricks 15 to 18, inclusive, showed significantly different amounts of efflorescence in the wick test, and the data for these are in a separate group.

The data of table 1 pertaining to bricks 1 to 14, inclusive, show the following:

1. When the rating of the bricks in the wick test was "considerable" (4), 16 of the 17 panels built from these bricks rated "moderate" (3) or more in the first inspection, and all of these rated "moderate" (3) or more in the second ins pection. 


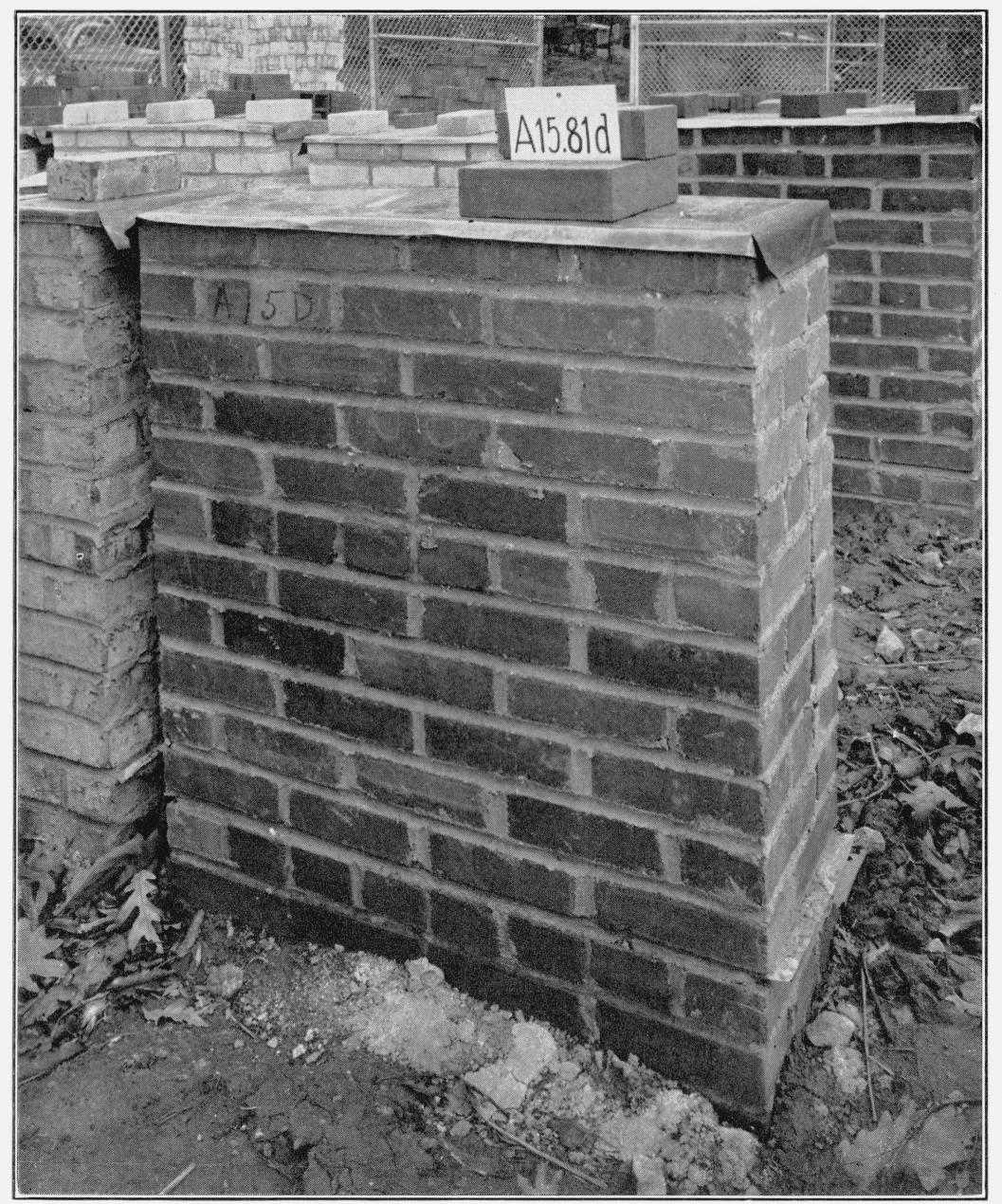

FIGURE 1.-Panel of brick, 2 showing sheet-copper cap over top and sheet-copper flashing above ground (protection d).

(Photograph taken Nov. 25, 1936.) 
2. When the rating of the bricks was "slight" (2) or less, 27 of the 32 panels of the bricks rated "moderate" (3) or less in the first inspection, and 31 of the 32 rated "moderate" (3) or less in the second inspection.

3. When the rating of the bricks was "trace" (1) or less, 22 of the 24 panels rated "moderate" (3) or less in the first inspection, and in the second inspection all rated "moderate" (3) or less and 20 of the 24 rated "slight" (2) or less.

4. The data presented do not show that the kind of protection had a significant effect on the amount of efflorescence on the panels.

It is evident that the correlation between the indications of the wick tests on the bricks and the appearance on efflorescence of the masonry was somewhat better for the data of the second than for the first inspection. Possibly data obtained during future inspections will show a continuance of this trend and also a significant difference in the appearance of panels with different protections $(b, c, d)$.

The panels built with bricks rating "none" (0) to "slight" tended to rate one or two grades higher than the individual bricks. Some of the efflorescence on these panels probably was caused by soluble salts originally in the mortar. The appearance of the panels during the first inspection indicated that salts from the mortar had contributed to the deposit. The efflorescence on most of the panels appeared on the exposed faces of the bricks and was chalk white in color; whereas, that on some of the panels of bricks rating "none" (0) was limited largely to the joints and edges of the bricks adjacent thereto and was gray in color.

\section{SUMMARY AND CONCLUSIONS}

The paper describes the wick test used at the National Bureau of Standards for indicating the tendency of bricks to be a source of efflorescence on masonry and outlines the scale of grading used in reporting and comparing the results. Comparisons are made between the performance of bricks in the test and the appearance of efflorescence on brick masonry exposed to the weather at Washington, D. C.

The results of the tests and comparisons showed that-

1. If considerable efflorescence appeared on bricks in the 5 -day wick test, masonry panels built of bricks of the same brand showed an objectionable (moderate or more) amount of efflorescence.

2. If the efflorescence on bricks in the wick test was only a trace or less most of the masonry panels built from the same brand of bricks showed only a slight (or less) amount of efflorescence.

3. Soluble salts from mortar appeared to have caused efflorescence on some of the panels.

Washington, May 14, 1937.

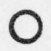

